\title{
Student Experience and Ubiquitous Learning in Higher Education: Impact of Wireless and Cloud Applications
}

\author{
Vladlena Benson, Stephanie Morgan \\ Kingston Business School, Kingston University, London, UK \\ Email: v.benson@kingston.ac.uk, stephanie.morgan@kingston.ac.uk
}

Received May $30^{\text {th }}, 2013$; revised June $30^{\text {th }}, 2013$; accepted July $7^{\text {th }}, 2013$

\begin{abstract}
Copyright (C) 2013 Vladlena Benson, Stephanie Morgan. This is an open access article distributed under the Creative Commons Attribution License, which permits unrestricted use, distribution, and reproduction in any medium, provided the original work is properly cited.
\end{abstract}

\begin{abstract}
Mobile learning apps for smartphones and tablet computer devices have entered Higher Education (HE) market. While universities are investing in new technologies, they also look into cost reduction strategies, including cloud computing. We draw upon a case study of a successful migration to mobile virtual environment and effective use of cloud computing at a UK university. Success factors and challenges of these emerging technologies in HE are discussed. The paper concludes with the consideration of student experience implications and research questions which need addressing in the area of ubiquitous learning.
\end{abstract}

Keywords: Student Experience; Mobile Learning Apps; Wireless; Cloud Solutions; Educational Technology; Higher Education

\section{Introduction}

Higher education institutions invest in technology to improve student experience and increase efficiency. Two recent technology trends are making an impact on the Higher Education sector. One, ubiquity of learning and teaching, translates into the move towards provision of wireless access to virtual learning environments (VLEs). Mobile VLE apps are emerging tailored to the variety of smart phones and tablet computers. The functionality of educational apps entering the market replicates the capabilities of the traditional VLEs. However, problems of software and device compatibility impede smooth transition to ubiquitous learning and teaching. The second trend, often associated with objectives of efficiency in HE, is focused on cloud computing. HE institutions traditionally maintained in-house IT departments and infrastructure. Under the pressure to achieve operational efficiency, using cloud computing as infrastructure appears as a sound investment for universities. However, issues of security and complex regulation need to be addressed for a successful provision of VLE services with cloud deployment. This paper considers the above trends in emerging technologies through the lens of student experience, an increasingly important area in today's competitive HE marketplace. The paper presents research questions in wireless learning and teaching for discussion. A case of a successful move to mobile learning enablement and cloud deployment concludes the paper and opens a discussion over the critical success factors in wireless e-learning operations.

\section{Ubiquity and Higher Education: Users Driving Adoption of Emerging Technologies}

Recent advancements in capabilities of mobile devices, both smart phones and tablet computers, have led to a significant rise in the penetration rate of wireless devices among the general population. Even more noticeable over recent years is the increasingly fast-growing rate of penetration of mobile devices among younger people. Students as true representatives of the "digital natives" generation (Prensky, 2001) are keen to explore new technologies. Mobile devices became a default method of accessing the Internet according to recent surveys (e.g. Internet in Britain 2011), while the number of UK mobile contract subscriptions have surpassed significantly UK population (Carphonewharehouse, 2011). According to the same source the migration rate of mobile subscribers to smartphones have reached $30 \%$ and this rate is even higher for such countries as Singapore (54\%), Hong Kong (35\%), USA (35\%), Australia (34\%) and Sweden (35\%). The proliferation of smart mobile devices and higher bandwidth of internet connections have had a significant impact in Higher Education. Virtual Learning Environments (VLEs) have been deployed by Higher Education (HE) institutions to provide access to learning materials and tools for students for over a decade. Advanced capabilities of mobile devices and better connectivity have led to a growing number of the student population accessing VLEs through their smart phones, downloading and working with lecture slides on iPads instead of paper notes, participating in VLE discussion forums through their phones, etc. With the growing number of mobile devices in the hands of the younger population, it is only a matter of time before HE students will be expecting wireless access to learning materials to complement and/or replace current Internet-based VLEs. The trend in HE today, mobility, is driven by the advanced capabilities and wide availability of mobile devices, from smart phones to tablet computers. The next step for HE is the highly anticipated but largely under researched move of the transition to mobile apps available for major mobile device manufacturers from Android to Apple. Extending student choice in this way will genuinely move the classroom out to any environment and remove all 
geographical and time constraints that have remained whilst access was required via a computer (the most flexible of which, the laptop, still requires wireless access, plug in to mobile, and large batteries or power source). Student demand for mobile access is likely to increase therefore, but this is likely to impact on HE systems efficiency.

\section{Achieving Efficiency in VLE Operations: Cloud Computing}

In search of efficiency and flexibility, higher education institutions are putting cloud computing, another current trend in HE sector, into practice. Current priorities of HE institutions include improving service delivery, reducing facility space usage and energy consumption. Many universities have to deal with spiralling costs of fragmented IT systems, poor IT project management and the complexity of legacy technology. All of these present barriers to achieving better performance and efficiency of VLE operations. Learning and teaching resources accumulated through the exploitation of VLEs for decades place spiralling demands on HE infrastructure, while service disruptions for upgrades and emergencies have a negative impact on students' experience. Students expect uninterrupted access to their learning materials, announcements, assessment results, etc. Infrastructure as a service presents an attractive cost effective option for virtual learning environment service delivery. Cloud computing offers many benefits, including pay-perusage models, improved flexibility, faster deployment of new services, decreased maintenance costs and reduced time spent on IT operations for an in-depth overview see e.g. (Winkler, 2011). Additionally, when outsourced to a dedicated service provider cloud services management is performed by professionals specializing in the field for whom quality of service delivery means their reputation. Cloud computing service providers have business continuity strategies, disaster recovery and security tools in place. Hence savings in terms of hardware operation and maintenance, software licensing and upgrades can be achieved by HE institutions when outsourcing VLE provision to a third party. While cloud platform as a service and software as a service technologies are still at the entry stage in the HE market, infrastructure as a service presents clear savings and improved reliability of data centre services.

\section{Achieving Improvement of Student Experience through Mobile and Cloud Solutions}

Mobile platforms for e-learning are an attractive solution to help engage the student community, enrich learning and help students throughout academic life. Blackboard Mobile Learn app, available on Android Marketplace, Blackberry App World or Apple App store, is one of the leading mobile platforms for e-learning. Students gain mobile access to their lecture materials, create discussion forums and posts, blog and comment on learning progress and resources.

The "digital natives" (Prensky, 2001) in higher education today are used to and surrounded by technology and increasingly expect mobile forms of communication. For HE professionals mobile learning is a way of extending the campus and offering students the opportunity to learn in whatever situation or context they prefer. What is unclear is to what extent they can and will learn in this increasingly informal and opportunistic mode. Social networking services are seen by many as the next level of learning management systems (Benson, Morgan, \& Tennakoon, 2012) promising convergence of social and learning tools. At present, though, mobile learning apps are offering another media for access of LMS repositories, doing the old things with a new tool.

Whilst mobile platforms for e-learning are still in the early development stages, it is imperative to consider issues needing research attention and improvement of software and wireless device capabilities, as well as pedagogical approaches to learning in mobile circumstances, in order to assess objectively technology's current and future impact on education.

According to a recent survey (LSE Focus, 2007) mobile devices are perceived as a significant contributor to maintaining quality of life. While for university students (BlackBoard, 2012) a smart phone represents a "key social connector and a learning tool". Higher Education institutions consider provision of mobile services to students to be an indicator of performance and better quality of student experience. Earlier approaches to integration of wireless devices into e-learning process (e.g. see Benson, 2008 for an overview) focused on access enablement to online content. The emergence of powerful and user friendly smart phones and tablet computers led to a proliferation of mobile apps, both from established elearning systems providers (e.g. BlackBoard) as well as independent companies and in house developments by Universities.

Current mobile apps from popular LMS providers are less than a year old. Blackboard Mobile Learn 2.0 offers a rich range of functionality with advanced usability features. Direct interface to the learning resources is a key feature of the app which enables students and instructors to access, create and upload content to the LMS. Blogs supporting media attachments, discussion forums and learning journal media features promise to bring interactive mobile learning to a new level. The user interface of the latest version of BlackBoard Mobile Learn supports adding most frequently accessed classes to favourite lists, this bookmarking feature helps manage and organise the learning and teaching process. The latest version of the app offers threaded hierarchy to improve the user interface while managing multiple tasks.

While the new features of the mobile apps are evolving, it is important to gain a better understanding of how ubiquitous access to study materials can improve learning outcomes. The impact of wireless technology on higher education is likely to be driven by student experience. Universities take on investment in mobile technology to improve student learning through wireless devices already at the fingertips of current students and beat the competition by demonstrating the importance of staying ahead of the technology curve. The use of the VLE has been shown to promote independent learning (e.g. Frederickson, 2005) and one could argue that extending this use to fully mobile access could further increase this. However as with a standard VLE students will need to be made aware of the purpose and benefits of using the mobile app, and care should be taken regarding design to encourage use. There is a risk that many download the app but do not use the system after the first attempt, removing all the benefits of developing these flexible approaches. It is vital therefore to assess critical success factors.

\section{Some of the Critical Success Factors to Consider}

Smartphones are effectively accepted by students either as a link to their social community or a favored learning tool, mo- 
bile apps have become a way of life for today's students. When making a choice of which university to apply for studying, whether or not an HE institution supports easy access to services or information in a way meaningful to technology savvy younger generation becomes a key differentiating factor.

- The app needs to be easy to access, fast and should be accessible on a range of mobiles (interoperable) to ensure that all students with a smart phone are able to use the system and interact.

- If support is needed the app will probably not be used although online help is likely to be viewed positively.

- The technological aspects will be taken for granted (unless they go wrong) and so the focus should be on a visually appealing, easy to use app that will allow students to share and enable informal and formal learning at the time and place that best suits their needs.

- Mobile experience is profoundly different to even a laptop, as it is available at all times and enables them to learn whilst relating to (in the world of) the concepts about which they are learning.

- Speed and continuity of service is vital, many legacy systems may not be able to cope, hence the need to consider outsourcing to cloud management providers.

\section{Examples of Pitfalls to Avoid}

The concept of cloud computing and wireless access to elearning application leaves several areas to consider. Capabilities of mobile devices present issues of access to learning and teaching resources, presentation of learning materials, navigation and compatibility of e-learning materials. On the other hand cloud as infrastructure as a service presents new challenges to HE in terms of security and compliance as data is being hosted by third parties outside of the corporate firewalls.

What students can see on the mobile learning app depends on at least two factors:

- The ability of a specific wireless device to display the variety of learning materials that may be included in the course content. For instance, iPhone, iPad and iPods running mobile operating system do not provide support for Flash. Therefore earlier e-learning materials developed using Flash will be inaccessible to Apple users.

- Instructors have control over which course content is available through the mobile app. Therefore options set so that only limited content is available to students should be carefully thought through by academic staff.

- Pedagogical reasons should drive the mobile learning platform development, rather than pure enthusiasm of a new gadget from technology-centric instructors (Benson \& Anderson, 2010).

- Students should have a clear understanding as to what materials are available through the mobile medium and why others are accessible only online, and how the mobile app can help improve their learning and their student experience on and off campus. As with all learning, particularly when technology is involved, explaining how and why different elements are designed in a particular way will facilitate learning (Ausburn, 2004).

Finally, migration to cloud computing needs special consideration. Unlike traditional outsourcing of IT management when typically organizations knew exactly where corporate data is hosted, how data is transported, managed and disposed of, cloud presents a different level of abstraction. Cloud computing separates data from infrastructure, hence the operational details of data whereabouts are obscured from the user. To illustrate this, the precise hardware location of any specific piece of data is difficult to identify. Multitenancy, (physical coexistence of data on the same hardware in a data centre), is almost certain in cloud as infrastructure services. Also, transport of data between the data centre and the corporate firewall give rise to security concerns. The differences between in house IT and cloud services management entail significant security and privacy issues that have an impact on university risk management practices and require careful consideration of legal issues in areas such as compliance and auditing. Personal student information, intellectual property of $\mathrm{HE}$ institutions in the form of learning and teaching materials are subject to regulation. The abstraction of infrastructure from data in the cloud requires addressing legal issues and application of security methods for successful deployment of cloud services in HE.

\section{A Case of a Successful Move to Mobile Platform with Cloud Computing}

As part of the student information system and learning management system (called StudySpace) upgrade, a Blackboard Mobile Learn application, available for iPhone, Blackberry and Android phones, has been launched by Kingston University, UK. The app allows students flexible mobile access to Study Space course content and communication tools, the downloadable app is accessible via the learning management system and QR code as shown in Figure 1.

The mobile platform solution was introduced in January 2012. By the start of the spring semester, the mobile learning app already had thousands of downloads. The rate of rapid adoption illustrates the impact of the mobile platform on the student population, as well as demand on computing services provided by Kingston University and external stakeholders. In the experience of other HE institutions, e.g. Stanford University (BlackBoard, 2012) the number of mobile learning app downloads tends to exceed the number of enrolled students. The impact of the mobile platform deployment has a wider impact not only on current students, but involves alumni, parents, and the greater community.

The capabilities of the StudySpace app at Kingston include access to course content and communication tools. Course materials most suitable for accessing on the go are enabled by instructors for mobile learning. One of the most well received features of the mobile app is instant communication capability.

Integration of mobile text messaging service with online announcements as well as a Facebook site for the university are tied in with individual courses and organization. This allows for seamless and unified communication means for students, staff, alumni and wider community. One of the key objectives of introducing the StudySpace mobile app is to improve student experience by increasing 24-7 access to learning technology that is not dependent upon location. This reflects the social, and increasingly work, environment to which students are accustomed.

Furthermore, it enables learning to move in and out of the classroom in a much easier manner than laptops as students invariably have their mobile with them, not always the case for other devices. Class activities including assessments could use and link to the mobile app (this also enables movement between 


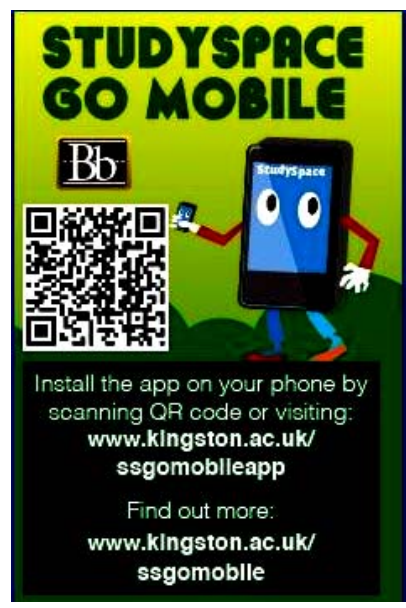

Figure 1.

Mobile app for VLE access.

classroom and workplace, for example, placements or workbased learning, see (Couldby, Hennessey, Davies, \& Fuller, 2011)).

The University also turned to cloud service management for its VLE provision. The choice of an EU based cloud hosting and storage service provider with careful consideration of regulatory frameworks ensured smooth deployment of cloud services. Flexible storage options of cloud computing offered University the highest levels of efficiency and interoperability. While VLE content is delivered to users faster and more efficiently. As VLE is accessed by students and university faculty from various countries content is distributed through a network with multiple nodes throughout the cloud, closer to the VLE end-users. This minimizes the distance the learning resources or messages have to travel, bypassing network overloads, decreasing latency, and improving the user experience. Business continuity measures have been improved by the move to the cloud provision which offered high availability solutions for VLE service delivery.

During the migration to cloud and BlackBoard mobile staff at all levels were well informed and engaged in the transition. Staff development exercises have taken place throughout the university, this is vital in ensuring successful transition. Students also welcomed the new IT project and enjoy the best of mobile and harness efficiency of flexible cloud services.

An unexpected advantage occurred when the legacy systems failed for a number of hours and students using the standard VLE often did not realize they could still access the cloud based systems if they went direct (in future the link will be included in the message), whereas students using the mobile app were still able to use the system. Again this demonstrates the importance of ensuring systems can cope with the increased usage and the potential benefit of using the cloud.

\section{Discussion}

Whilst the mobile platform appears a lucrative solution for engaging learners on and off campus (Benson, 2008), the Blackboard app still suffers drawbacks. User ranking of the Blackboard Mobile Learn for Android (GooglePlay, 2012) phones averages at only 2.6 out of 5 (based on 6196 reviews) according to Google Play data in 2012. The app version for iPhone and iPad (iTunes, 2012) also lags behind in user re- viewers ( 2.5 stars from 2420 users) based on iTunes user feedback. So what challenges are ahead of developers and academic staff alike to help make a mobile learning platform fulfill its objective to increase the quality of student experience and improve learning and teaching?

There are several levels of challenge to address, including application dependent, service dependent, compliance related and pedagogical underpinning of the mobile technology.

Application dependent issues reported on the BlackBoard Mobile user reviews revolve around the following:

- Compatibility problems - having downloaded the app students were unable to find their institution or reported messages of "your institution does not support" the app.

- Application failure - when accessing PowerPoint slides app "crashes". Conversion of files to PDF formats causes application failure.

Device support issues - individual wireless devices will have an impact on what resources are available and how they will be presented to the user. One of the most notorious support issues affecting a wide range of existing learning materials is the Flash vs Apple support. BlackBoard Mobile Learn and other apps base their popularity on their support for a variety of wireless devices but pockets of unsupported functionality and varied presentation between devices remains.

Service provision problems reported relate to speed of the app loading resources. Slow download rate of the communication tools and learning resources are the main causes of concern for mobile app users. On the other hand, service availability of the VLE maintained by universities in-house is quite an important factor in student satisfaction.

By moving VLE service provision to the cloud, service quality and reliability improves. However, issues of privacy and security of data transported between cloud service provider and users on or off campus creates a number of concerns. These include regulatory issues around personal data storage and management, communication of data across borders and other compliance issues. On the other hand outsourcing of VLE hosting to a cloud provider enhances security and reliability of services as the professional approach of many cloud vendors may mean better security as well as business continuity.

Finally, pedagogical underpinning of the mobile learning apps is far from maturity. How to ensure that students are not lost in "virtual learning space"? How to deliver a meaningful learning experience through a powerful mobile platform but yet limited in its capabilities at present?

The pedagogic implications of developing systems that are sufficiently simple to work well on an app but challenging and interesting to students, and the extent to which students can and will learn using these technologies, have yet to be explored. There may be exciting new pedagogical approaches that can be taken to make full use of the potential of mobile.

All aspects of the technology potential should be assessed to consider what new learning experiences we can offer students. What we can be certain of is that students will increasingly expect these services, and they will expect them to work well. Indeed HE institutions that are able to truly innovate and enhance learning with mobile apps, working around the challenges above, could gain ground quickly.

\section{Student Experience and Emerging Technologies}

Students graduating today will find increased competition for 
jobs, and will be expected to work in a global economy, for many they will be part of a global collaborative environment communicating without borders. They are already involved in mobile communities through Facebook and twitter, and will increasingly expect $\mathrm{HE}$ environments to mirror this lifestyle and prepare them for the "wired" world. At the same time, Universities need to stay current and relevant to attract and retain students. Whether mobile learning is student led or University led, it is likely to become increasingly important.

The mobile VLE can improve student experience by enhancing engagement, enabling collaboration both formal and informal with peers and related communities, in an immediate and modern manner. Our initial student feedback of the system suggests they are enthusiastic at first, and it is viewed as innovative. Certainly offering a mobile VLE extends student choice regarding when where and how they learn, is likely to enhance independent learning, and also collaborative learning. As with any learning tool though it will be vital to ensure the students understand the purpose and benefits of the mobile offer, and are encouraged to actually use it through good course design and blended learning - using the mobiles in class and on campus as well as outside the institution.

There is some evidence that many students download the app, adding it to their long list of available tools, and then promptly forget about it, or try once and then give up. The technical issues and purposive use of engagement-led content will be important to success. We have highlighted some critical issues and some student demands, but far more research is needed to fully understand good practice. Research questions should focus on actual student experience of mobile learning and which forms of mobile activity, in which contexts, generate deep learning and student engagement.

\section{Conclusion}

Over the past year the Higher Education (HE) sector has experienced a move to wireless learning enabled through mobile apps. Advanced features of smart phones and tablet computers have sent the penetration rate of mobile devices soaring amongst students. Universities are investing in mobile applications enabling wireless access to current Virtual Learning Environments while carefully considering the benefits of the cloud for secure and flexible provision of VLE services. Capabilities of wireless devices present issues of access, presentation and compatibility of e-learning materials, while cloud as infrastructure as a service raises concerns of security as data is hosted by third parties outside of the corporate firewalls. A case of a successful move to mobile learning enablement and cloud deployment opens the discussion around the critical success factors in wireless e-learning operations. We have considered research questions through the lens of student experience and call for further research attention to the pedagogical underpinning of wireless learning technology.

\section{Acknowledgements}

The authors would like to thank the Academic Development Centre and Student Information Services at Kingston University for their help and advice in development of this paper.

\section{REFERENCES}

Ausburn, L. J. (2004). Course design elements most valued by adult learners in blended online education environments: An American perspective. Educational Media International, 41, 327-337. doi: $10.1080 / 0952398042000314820$

BlackBoard.com. (2012). Transforming the experience with blackboard mobile.

Benson, V. (2008). Unlocking the potential of wireless learning. Learning and Teaching in Higher Education, 2, 42-56.

Benson, V., \& Anderson, D. (2010). Towards a strategic approach to the introduction of blended learning: Challenges faced and lessons learned. British Journal of Educational Technology, 41, E129-E131. doi:10.1111/j.1467-8535.2010.01066.x

Benson, V., Morgan, S., \& Tennakoon, H. (2012). Social networking: A knowledge convergence platform. International Journal of Knowledge Society Research, 6, 56-74.

Carphonewarehouse Penetration Rate of SmartPhones (2011). 42 major countries ranked by smartphone penetration rates. http://www.wired.com/beyond the beyond/2011/12/42-major-countr ies-ranked-by-smartphone-penetration-rates/

Coulby, C., Hennessey, S., Davies, N., \& Fuller, R. (2011). The use of mobile technology for work-based assessment: the student experience. British Journal of Educational Technology, 42, 251-265. doi:10.1111/j.1467-8535.2009.01022.x

Frederickson,N., Reed, P., \& Clifford, M. (2005). Evaluating Websupported learning versus lecture-based teaching: Quantitative and qualitative perspectives. Higher Education, 50, 645-664. doi:10.1007/s10734-004-6370-0

Google Play (2012) Android store user reviews. https://play.google.com/store/apps/details?id=com.blackboard.androi $\mathrm{d} \& \mathrm{hl}=\mathrm{en}$

iTunes (2012). iTune Store BlackBoard Mobile Learn App User Reviews.

http://itunes.apple.com/us/app/blackboard-mobile-learn/id364252826 $? \mathrm{mt}=8$

Internet in Britain Report (2011). OxSIS Internet in Britain Survey.

LSE Focus (2007). Mobile life Report 2007: The connected world. London: Focus LSE. http://www.mobilelife2007.co.uk/

Prensky, M. (2001). Digital natives, digital immigrants, Part II: Do they really think differently? On the horizon (pp. 1-7). NCB University Press.

Winkler, V. (2011). Securing the cloud: Cloud computer security techniques and tactics (p. 57). Waltham, MA: Elsevier.

(2013). Learn. http://www.blackboard.com/Platforms/Mobile/ 